\title{
Clinical Factors Associated with New-Onset Glucose Intolerance among Patients with Schizophrenia during Clozapine Treatment: All-Case Surveillance in Japan
}

\author{
Mikiko Ishibashi, ${ }^{1}$ Kentaro Matsui, ${ }^{1,2,3, *}$ Masahiko Kawano, ${ }^{4}$ Hidehiro Oshibuchi, ${ }^{1}$ \\ Jun Ishigooka, ${ }^{5}$ Katsuji Nishimura ${ }^{1}$ and Ken Inada ${ }^{1, *}$ \\ ${ }^{1}$ Department of Psychiatry, Tokyo Women's Medical University, Tokyo, Japan \\ ${ }^{2}$ Department of Clinical Laboratory, National Institute of Mental Health, National Center of Neurology and \\ Psychiatry, Kodaira, Tokyo, Japan \\ ${ }^{3}$ Department of Sleep-Wake Disorders, National Institute of Mental Health, National Center of Neurology and \\ Psychiatry, Kodaira, Tokyo, Japan \\ ${ }^{4}$ Miyakonojo Shinsei-Hospital, Miyakonojo, Miyazaki, Japan \\ ${ }^{5}$ Institute of CNS Pharmacology, Tokyo, Japan
}

Clozapine (CLZ), an antipsychotic with a unique mechanism of action, is known to be superior to any other antipsychotic for schizophrenia. However, CLZ is also known to be associated with the development of lethal side effects, which include agranulocytosis and glucose intolerance (GI). Regular measurement and registration of blood test results have been mandatory for all CLZ users; however, these risks may still prevent therapists from prescribing CLZ. While CLZ-induced agranulocytosis has been well documented, CLZ-induced GI in the real world has not been fully investigated. Therefore, in this study, we used data registered in monitoring systems to investigate background factors associated with new-onset $\mathrm{Gl}$ after CLZ administration and changes in $\mathrm{HbA} 1 \mathrm{c}$ levels during CLZ treatment. Data of all patients with schizophrenia who were using CLZ from July 29, 2009 to January 20, 2016 were used for the analysis. Of the 3,746 patients enrolled in the study, $92(2.5 \%)$ had $\mathrm{Gl}$ at baseline; of the remaining 3,654 patients, $428(11.7 \%)$ developed new-onset GI. Multivariate logistic regression analysis revealed that the development of new-onset GI was significantly associated with older age, higher baseline $\mathrm{HbA} 1 \mathrm{c}$ levels, and longer treatment duration. In patients with $\mathrm{Gl}$ at baseline, $\mathrm{HbA} 1 \mathrm{c}$ levels were maintained or improved over 18 months, while in the other patients, CLZ administration gradually elevated HbA1c levels. The findings of this study suggest that, although adequate monitoring and intervention is required, CLZ induction and maintenance therapy may be safe, even for patients with impaired glucose tolerance.

Keywords: clozapine; drug-induced hyperglycemia; glucose intolerance; HbA1c; schizophrenia Tohoku J. Exp. Med., 2020 October, 252 (2), 177-183.

\section{Introduction}

Schizophrenia is one of the major mental disorders with a high lifetime prevalence of approximately $0.72 \%$ (Saha et al. 2005). It involves a complex series of disturbances in thinking, perceiving, feeling, and social behavior (American Psychiatric Association 2013). It follows a chronic course and is a serious public health problem that places a heavy burden on patients, caregivers, and society (American Psychiatric Association 2013). The typical treat- ment for schizophrenia is pharmacotherapy with antipsychotic medication. However, response to available antipsychotic medications varies between patients (Lehman et al. 2004; Tiihonen et al. 2017; Taipale et al. 2018), with around $30 \%$ of patients not achieving adequate response to conventional antipsychotics (Meltzer 1997; Lehman et al. 2004; Solanki et al. 2009; Correll et al. 2019).

Clozapine (CLZ) has been shown to be an effective therapy for treatment-resistant schizophrenia (TRS) (Chakos et al. 2001; Lewis et al. 2006; McEvoy et al. 2006;

Received May 7, 2020; revised and accepted September 18, 2020. Published online October 13, 2020; doi: 10.1620/tjem.252.177.

*These two authors contributed equally to this work.

Correspondence: Ken Inada, M.D., Ph.D., Department of Psychiatry, Tokyo Women's Medical University, 8-1 Kawadacho, Shinjuku-ku, Tokyo 162-8666, Japan.

e-mail: inada.ken@twmu.ac.jp

C 2020 Tohoku University Medical Press. This is an open-access article distributed under the terms of the Creative Commons Attribution-NonCommercial-NoDerivatives 4.0 International License (CC-BY-NC-ND 4.0). Anyone may download, reuse, copy, reprint, or distribute the article without modifications or adaptations for non-profit purposes if they cite the original authors and source properly.

https://creativecommons.org/licenses/by-nc-nd/4.0/ 
Leucht et al. 2009; Asenjo Lobos et al. 2010). CLZ, like many other antipsychotics, is a dopamine $\mathrm{D}_{2}$ receptor antagonist; however, it has affinities to serotonin 5-hydroxytryptamine $(5-\mathrm{HT})_{2 \mathrm{~A}}, 5 \mathrm{HT}_{2 \mathrm{C}}, 5-\mathrm{HT}_{6}, 5-\mathrm{HT}_{7}$, dopamine $\mathrm{D}_{4}$, muscarine $\mathrm{M}_{1}$, and $\alpha_{1}$-adrenergic receptors, which are greater than its affinity for the $\mathrm{D}_{2}$ receptor (Meltzer 1994). These various receptor antagonistic actions, together with its weak $\mathrm{D}_{2}$ blocking properties have been speculated to contribute to a superior antipsychotic effect to other antipsychotics (Meltzer 1994; Nucifora et al. 2017). In addition to improving psychotic symptoms, CLZ has been shown to reduce mortality (Hayes et al. 2015), reduce suicide risk (Meltzer et al. 2003; Tiihonen et al. 2009), improve cognitive functioning (Grace et al. 1996; Galletly et al. 1997) and improve quality of life (Meltzer et al. 1990). Despite these clinical advantages, CLZ is also associated with a risk of fatal agranulocytosis (Lieberman and Safferman 1992). Thus, to detect and manage serious blood dyscrasia, many countries have established mandatory systems for monitoring the blood of CLZ patients (Alvir et al. 1993; Atkin et al. 1996; Copolov et al. 1998; Lambertenghi Deliliers 2000; Kang et al. 2006; Balda et al. 2015). In Japan, where CLZ was approved for the treatment of TRS in 2009, all patients must be registered with the Clozaril Patient Monitoring Service (CPMS) for regular blood monitoring.

In addition to agranulocytosis, patients using CLZ show an increased risk of various poor metabolic outcomes, including weight gain (Henderson et al. 2000; Taylor and McAskill 2000; Rummel-Kluge et al. 2010), type 2 diabetes (Henderson et al. 2000, 2005; Cohen and Correll 2009; Nielsen et al. 2010), dyslipidemia (Henderson et al. 2000, 2005; Casey 2004; Meyer and Koro 2004) and hypertension (Henderson et al. 2004). In particular, CLZ has been reported to cause glucose intolerance (GI) more frequently than other antipsychotics (Rummel-Kluge et al. 2010) and this may result in death from hyperglycemic crises such as diabetic ketoacidosis and diabetic coma (Cohen and Correll 2009; Nielsen et al. 2010). However, because previous patient surveys did not include data on blood glucose or glycosylated hemoglobin (HbA1c) levels (Alvir et al. 1993; Atkin et al. 1996; Copolov et al. 1998; Lambertenghi Deliliers 2000; Kang et al. 2006; Balda et al. 2015), the background, prevalence, and course of CLZ-induced GI remain unclear.

Our research group previously evaluated the prevalence of CLZ-induced GI using CPMS data in Japan and found that $12.8 \%$ of patients developed new-onset GI after initiating CLZ treatment (Inada et al. 2018); however, no further details on CLZ-induced GI were investigated. The objective of this study was to clarify factors associated with GI in a real-world clinical setting. For this purpose, we reanalyzed the CPMS data in Japan and investigated the background factors associated with new-onset GI after CLZ administration and changes in HbAlc levels during CLZ treatment.

\section{Materials and Methods}

\section{Clinical setting of CLZ initiation}

The use of CLZ in Japan is approved only for TRS, which can be defined as follows: 1) schizophrenia for which treatment with two or more antipsychotics (at least one of which is an atypical antipsychotic) at doses equivalent to $\geq$ $600 \mathrm{mg} / \mathrm{d}$ of chlorpromazine for at least 4 weeks does not produce an adequate response or 2) schizophrenia for which treatment with two or more atypical antipsychotics is attempted, but the doses cannot be increased sufficiently owing to extrapyramidal symptoms. As a general principle, CLZ treatment is initiated during hospitalization, and patients remain in hospital while being followed up for up to 18 weeks. However, if no changes in the CLZ dose are necessary for more than 1 week, and an observer regularly records the patient's symptoms, medication intake and hospital visits, then that patient can be transferred to outpatient treatment after 3 weeks of hospitalization. Exclusively in Japan, rules state that all patients must be hospitalized on introduction to CLZ. The CLZ dose is typically increased from $12.5 \mathrm{mg} / \mathrm{d}$ to $200 \mathrm{mg} / \mathrm{d}$ over a period of 3 weeks and subsequently by up to $100 \mathrm{mg} /$ day at intervals of $4 \mathrm{~d}$ or longer; the maximum daily dose is $600 \mathrm{mg} / \mathrm{d}$. All patients taking CLZ undergo blood testing at least once every 2 weeks to determine the leukocyte and neutrophil counts; these data, and the CLZ dose, are registered with the CPMS throughout the period of CLZ treatment. Additionally, $\mathrm{HbA} 1 \mathrm{c}$ and blood glucose (fasting or casual) levels are registered with the CPMS at the initiation of CLZ and at 1 and 3 months after initiation, and every 3 months thereafter. Blood glucose levels and $\mathrm{HbA} 1 \mathrm{c}$ are measured at least once every 4 weeks and registered with the CPMS if any of the following apply: fasting blood glucose levels are $110 \mathrm{mg} /$ $\mathrm{dL}$ or higher; casual blood glucose levels are $140 \mathrm{mg} / \mathrm{dL}$ or higher; or HbAlc levels are $6.0 \%$ or higher.

\section{Study population}

The present study extracted unlinkable and anonymized data that had been registered with the CPMS from July 29, 2009 to January 20, 2016; these data included age at initiation of CLZ, sex, dose of CLZ at each hospital visit, blood glucose levels (fasting or casual) and $\mathrm{HbA} 1 \mathrm{c}$ levels. Individual patients who consecutively received CLZ at different hospitals were treated as the same case, whereas patients who were re-enrolled after stopping treatment were treated as separate cases (Inada et al. 2018). Of the 3,780 patients who were eligible for the present study, 3,746 were included in the analysis; 34 patients who were registered with CPMS but did not receive CLZ were excluded, which differs from our previous report (Inada et al. 2018). Institutional Review Board approval was not required because the database used in this study only contains anonymized data. 


\section{Outcomes and statistical analysis}

In our previous report (Inada et al. 2018), GI was defined according to the guidelines of the Japanese CPMS: fasting blood glucose level $\geq 126 \mathrm{mg} / \mathrm{dL}$, casual blood glucose level $\geq 180 \mathrm{mg} / \mathrm{dL}$, or HbAlc level $\geq 6.5 \%$; however, the criteria were designed to detect in advance, patients at risk for progression to diabetes. On the basis of the current diagnostic criteria for diabetes (American Diabetes Association 2014), GI in the present study was defined as fasting blood glucose level $\geq 126 \mathrm{mg} / \mathrm{dL}$, casual blood glucose level $\geq 200 \mathrm{mg} / \mathrm{dL}$, or $\mathrm{HbA} 1 \mathrm{c}$ level $\geq 6.5 \%$. In the present study, the patients were divided into three groups, i.e., those with GI at baseline, new-onset GI and no GI during the observation period (control).

The three groups were compared using Chi-squared tests for categorical variables and Kruskal-Wallis tests followed by Dunn's multiple comparison tests for continuous variables. The incidence of new-onset GI was assessed after excluding patients with GI at baseline and logistic regression analyses were performed to identify the factors (such as age, sex, HbA1c level at baseline, treatment duration and cumulative dose of CLZ) associated with newonset GI. All variables were analyzed in univariate logistic regression analyses and significant factors were included in a multivariate logistic regression analysis.

To evaluate $\mathrm{HbA} 1 \mathrm{c}$ levels, the baseline data, and those from 1, 3 and 6 months after the initiation of CLZ were obtained for all patients in each group treated with CLZ for 6 months or longer. Similarly, to assess changes in HbA1c levels, the baseline data, and those from 6,12, 18 and 24 months after the initiation of CLZ were obtained for all patients in each group treated with CLZ for 24 months or longer. In all assessments, Kruskal-Wallis tests followed by Dunn's multiple comparison tests were performed in each group to compare the $\mathrm{HbAlc}$ level at the different timepoints with the level at baseline. SPSS software (version 20.0; SPSS Japan, Inc., Tokyo, Japan) was used to conduct all analyses and $p$ values $<0.05$ were considered to indicate statistical significance.

\section{Results}

\section{Patient characteristics}

Of the 3,746 patients included in the present study, $2,015(53.8 \%)$ were men (Table 1). The mean (S.D.) values for age (years), HbAlc level at baseline (\%), treatment duration (week), maximum daily dose of CLZ (mg/d) and cumulative dose of CLZ (g) were 40.5 (12.2), 5.23 (0.55), 91.7 (82.0), 381.0 (180.2) and 227.8 (256.1), respectively. Regarding GI, 92 patients (2.5\%) had GI at baseline, 428 (11.4\%) showed new-onset GI and 3,226 (86.1\%) did not show GI (control). Age and HbA1c level at baseline were significantly higher in the GI at baseline and new-onset GI groups than in the control group (age: 46.9 (10.6) years and 45.0 years (12.3) vs. 39.8 years (12.1), respectively; HbA1c level: $7.22 \%(1.34)$ and $5.38 \%(0.49)$ vs. $5.16 \%(0.38)$, respectively; all $p<0.001)$. Additionally, compared with the control group, the new-onset GI group had a significantly longer treatment duration (85.5 weeks (79.6) vs. 138.6 weeks (86.4), respectively; $p<0.001)$ and significantly higher maximum daily $(\mathrm{mg} / \mathrm{d})$ and cumulative $(\mathrm{g})$ doses of CLZ (daily: 377.7 (180.1) vs. 424.2 (162.7), respectively; cumulative: 212.3 (247.6) vs. 347.0 (291.0), respectively; all $p<0.001)$. There were no significant differences in sex ratio between the groups.

\section{Factors associated with new-onset GI}

The incidence of new-onset GI in the present study was $11.7 \%$ (428 of 3,654 patients, excluding those with GI at baseline) and occurred a mean (S.D.) of 56.7 (61.1) weeks after the initiation of treatment, with a mean (S.D.) CLZ dose of 317.5 (169.9) mg/d. Multivariate logistic regression analysis revealed that the development of newonset GI was significantly associated with older age (odds ratio $(\mathrm{OR})=1.031,95 \%$ confidence interval $(\mathrm{CI})=1.022$ 1.041), a higher HbA1c level at baseline ( $\mathrm{OR}=6.916,95 \%$ $\mathrm{CI}=5.144-9.298)$ and a longer treatment duration $(\mathrm{OR}=$ $1.011,95 \% \mathrm{CI}=1.010-1.012$; all $p<0.001)$ (Table 2).

\section{Changes in HbAlc levels}

Of the 2,623 patients who were treated with CLZ for more than 6 months, $66(2.5 \%)$ had GI at baseline, 387

Table 1. Descriptive statistics of patients.

\begin{tabular}{lccc}
\hline & GI at baseline $(\mathrm{n}=92)$ & New-onset GI $(\mathrm{n}=428)$ & Control $(\mathrm{n}=3,226)$ \\
\hline Sex (\% Male) & 44.6 & 54.4 & 54.0 \\
Age, mean (S.D.), year & $46.9(10.6)^{*}$ & $45.0(12.3)^{*}$ & $39.8(12.1)$ \\
HbAlc at baseline, mean (S.D.), \% & $7.22(1.34)^{*}$ & $5.38(0.49)^{*}$ & $5.16(0.38)$ \\
Treatment duration, mean (S.D.), week & $85.5(70.2)$ & $138.6(86.4)^{*}$ & $85.5(79.6)$ \\
Maximum daily dose of cloazapine, mean (S.D.), mg/day & $369.7(178.9)$ & $424.2(162.7)^{*}$ & $377.7(180.1)$ \\
Cumulative dose of clozapine, mean (S.D.), g & $199.6(202.5)$ & $347.0(291.0)^{*}$ & $212.3(247.6)$ \\
\hline
\end{tabular}

Control was defined as patients who did not show GI during the observation period. All data were analyzed with Chi-squared tests for categorical variables and Kruskal-Wallis tests followed by Dunn's multiple comparison tests for continuous variables. GI, glucose intolerance; S.D., standard deviation.

$* p<0.001$ compared with control. 
Table 2. Factors associated with new-onset glucose intolerance.

\begin{tabular}{|c|c|c|c|c|c|}
\hline Predictor & & Univariate Relative Risk $(95 \% \mathrm{CI})^{1)}$ & $p$ & Multivariate Relative Risk $(95 \% \mathrm{CI})^{1)}$ & $p$ \\
\hline Age (year) & 3,654 & $1.034(1.026-1.042)$ & $<0.001$ & $1.031(1.022-1.041)$ & $<0.001$ \\
\hline \multicolumn{6}{|l|}{ Sex } \\
\hline Male & 1,974 & & & & \\
\hline Female & 1,680 & & n.s. & & n.s. \\
\hline HbA1c at baseline (\%) & 3,654 & $4.034(3.120-5.216)$ & $<0.001$ & $6.916(5.144-9.298)$ & $<0.001$ \\
\hline Treatment duration (week) & 3,654 & $1.007(1.006-1.008)$ & $<0.001$ & $1.011(1.010-1.012)$ & $<0.001$ \\
\hline Cumulative dose of clozapine $(\mathrm{g})$ & 3,654 & $1.002(1.001-1.002)$ & $<0.001$ & & n.s. \\
\hline
\end{tabular}

Each variable was first examined in a univariate model. Multivariate logistic regression analysis was then performed on all variables significantly correlated in the univariate model.

CI, confidence interval; n.s., not significant.

${ }^{1)}$ Relative risk approximated to odds ratio.
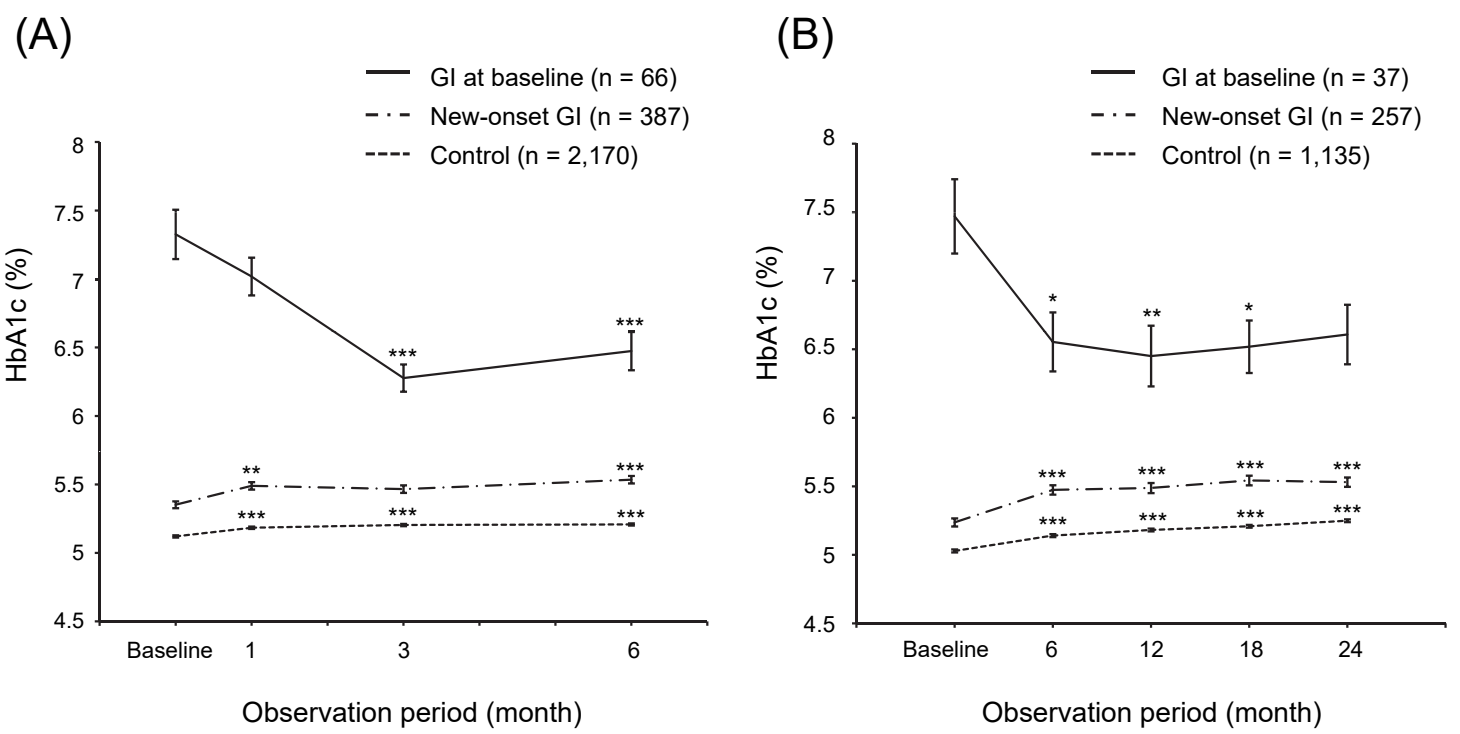

Fig. 1. Changes in HbAlc levels over time.

Line graphs showing mean HbAlc levels of the three groups of patients (glucose intolerance [GI] at baseline, new-onset GI, and control) who were treated with clozapine (CLZ). The groups were divided into treatment periods of (A) more than 6 months $(n=2,623)$ and $(B)$ more than 24 months $(n=1,429)$. Controls were defined as patients who did not show GI during the observation period. All data are presented as mean \pm standard error and were analyzed with Kruskal-Wallis tests followed by Dunn's multiple comparison tests. $* * * p<0.001$ compared with baseline HbA1c.

$* * p<0.01$ compared with baseline HbAlc. $* p<0.05$ compared with baseline HbAlc.

(14.8\%) showed new-onset GI and 2,170 (82.7\%) did not show GI (control, Fig. 1A). The mean HbAlc (S.E.) levels in the GI at baseline group at baseline and at 1,3 , and 6 months after administration were $7.33(0.18), 7.02(0.14)$, $6.28(0.10)$ and $6.47(0.14)$, respectively. The levels in the new-onset GI group at baseline and at 1,3 , and 6 months after administration were 5.35 (0.03), 5.49 (0.03), 5.47 $(0.03)$ and $5.54(0.03)$, respectively. The levels in the control group at baseline and at 1,3 , and 6 months after administration were $5.12(0.01), 5.18(0.01), 5.20(0.01)$ and 5.21 (0.01), respectively. Compared with the baseline levels of each group, the $\mathrm{HbAlc}$ levels were significantly lower at 3 and 6 months in the GI at baseline group $(p<0.01$ and $p<$
0.001 , respectively), significantly higher at 1 and 6 months in the new-onset GI group (all $p<0.001$ ) and significantly higher at 1,3 , and 6 months in the control group (all $p<$ 0.001 ).

Of the 1,429 patients treated with CLZ for more than 24 months, $37(2.6 \%)$ had GI at baseline, 257 (18.0\%) showed new-onset GI and 1,135 (79.4\%) did not show GI (control; Fig. 1B). The mean HbA1c (S.D.) values at baseline, and at $6,12,18$ and 24 months after administration, were $7.47(0.27), 6.55(0.22), 6.45(0.22), 6.52(0.19)$ and $6.61(0.22)$, respectively, in the GI at baseline group. In the new-onset GI group the mean $\mathrm{HbAlc}$ (S.E.) values at baseline, and at 6, 12, 18 and 24 months after administration 
were $5.24(0.03), 5.47(0.03), 5.49(0.04), 5.54(0.04)$ and $5.53(0.03)$, respectively, and in the control group were 5.03 (0.01), $5.14(0.01), 5.18(0.01), 5.21(0.01)$ and $5.25(0.01)$, respectively. Compared with the baseline levels of each group, the HbA1c levels were significantly lower at 6,12 and 18 months in the GI at baseline group ( $p<0.05, p<$ 0.01 and $p<0.05$, respectively) and significantly higher at $6,12,18$ and 24 months in the new-onset GI and control groups (all $p<0.001$ ).

\section{Discussion}

To our knowledge, this is the first study to examine the factors associated with CLZ-induced GI and changes in HbAlc levels using an all-patient surveillance approach. The primary finding of the present study was the difference in the time courses of HbAlc levels; HbAlc levels decreased in patients with GI at baseline, whereas they gradually increased in patients with new-onset GI and in the control group. The findings of the new-onset GI and control groups are consistent with previous studies that showed that CLZ may aggravate GI (Henderson et al. 2000, 2005; Cohen and Correll 2009; Nielsen et al. 2010). However, of note, HbAlc levels decreased for at least 18 months after the initiation of CLZ in patients with GI at baseline in this study. These findings may be important, even though the overall mean HbAlc levels in the GI at baseline group were higher than the thresholds for GI (HbAlc level $\geq 6.5 \%$ ) (American Diabetes Association 2014). It is possible that the hospitalization of the patients influenced their HbAlc levels, because this type of clinical setting tends to improve the nutritional intake of patients (Suzuki et al. 2013). All patients in the present study were hospitalized for at least 3 weeks from initiation of CLZ treatment, although the durations of subsequent hospitalizations are unknown. Few studies have assessed the duration of hospitalization after initiating CLZ in Japan. However, one study reported that $44 \%$ of patients were discharged from the hospital within 18 weeks (Enomoto et al. 2013). Thus, the GI may have continued to improve even after some patients were transferred to outpatient settings. Accordingly, it is possible that the primary reason for the persistently low HbA1c levels was the CPMS itself, because it may lead to appropriate therapeutic interventions such as referral to a diabetes specialist. Serious antipsychotic drug-induced GI is reported to occur in the acute phase of treatment (Koller et al. 2001), but this can be prevented by appropriate monitoring and intervention. Differences in the incidence of GI in patients with, versus without, regular monitoring should be evaluated in future studies. It is also possible that the decline in $\mathrm{HbA} 1 \mathrm{c}$ levels observed in the present study was due to cognitive improvements. For example, CLZ treatment has shown an association with weight loss (Thomas et al. 2009; Hanwella et al. 2010; Appiani et al. 2011; Lally and McDonald 2011; Webster and Ingram 2013; Tungaraza 2016) and some case reports have indicated that improvements in cognitive func- tion due to CLZ treatment increased patients' interest in diet and exercise, which resulted in decreased body weight (Appiani et al. 2011; Lally and McDonald 2011). Because psychopathologies and cognitive function were not evaluated in the present study, further studies will be necessary to clarify the correlations between improvements in psychotic symptoms and/or cognitive function and $\mathrm{HbAlc} \mathrm{lev-}$ els after the initiation of CLZ.

Both higher age and HbAlc levels were suggested as background factors for CLZ-induced GI in the present study. This is consistent with the results of previous studies of CLZ-treated patients (Henderson et al. 2000; Sernyak et al. 2003) and the general population (Diabetes Prevention Program Research Group 2015). In addition, in our study, the treatment duration was significantly longer and the maximum and cumulative doses of CLZ were significantly higher in the new-onset GI group compared with the control group. These findings suggest that new-onset GI was more likely to occur during longer treatment duration, possibly because of the gradual increase in HbA1c levels. Moreover, in the present study, the incidence of new-onset GI was correlated with treatment duration, but not with cumulative dose of CLZ. Although the mechanisms remain unclear, the difference may be due to individual differences in the sensitivity to, and metabolism of, CLZ. The effect of interactions with other medications on GI can also be considered, however, this was not controlled in the present study. Further research will be necessary to determine whether treatment duration or cumulative dose is a greater risk factor for GI, given the interaction effect of combining drugs.

The present study had several limitations that should be considered. First, GI was defined solely based on blood samples, and not on data from medical examinations by a physician. Although patients with an elevated HbAlc level are more likely to be referred to a physician, no data from any such referrals were available in the present study. Moreover, there was a lack of information regarding concomitant medications that could potentially influence glucose metabolism. Similarly, the known risk factors of diabetes, such as family history thereof, body mass index, blood pressure and serum lipids, were not controlled for in the present study. Second, the severity of the positive and negative symptoms of schizophrenia, and the quality of cognitive and social functioning, which could influence the likelihood of GI, were not evaluated. Third, although in some of the cases in the present study CLZ might have been discontinued because of GI, the reasons for discontinuation of CLZ were unclear. Fourth, although rare, in several cases data from re-enrolled subjects were counted separately; the precise number of such cases was unclear. Fifth, the race and/or ethnicity of the subjects was not controlled for, which is important because racial differences in glucose metabolism have been reported (Kodama et al. 2013).

In conclusion, the present results showed that $\mathrm{HbAlc}$ levels tended to increase with CLZ treatment, suggesting that there was a risk of treatment-induced GI, and that the 
duration of CLZ treatment was associated with the occurrence of new-onset GI. In contrast, the $\mathrm{HbA} 1 \mathrm{c}$ levels of patients with GI at baseline were either maintained or decreased during CLZ treatment, which might have resulted from appropriate monitoring and medical interventions. Given the high therapeutic efficacy of CLZ, clinicians should consider administering it in conjunction with close monitoring, even if a patient has GI or diabetes.

\section{Acknowledgments}

This research was partially supported by Health Labour Sciences Research Grant, Japan (20GC1017).

We thank Melony Black, Ph.D., and Sarina Iwabuchi, Ph.D., from Edanz Group (https://en-author-services.edanzgroup.com/ac) for editing a draft of this manuscript.

\section{Conflict of Interest}

The authors declare no conflict of interest.

\section{References}

Alvir, J.M., Lieberman, J.A., Safferman, A.Z., Schwimmer, J.L. \& Schaaf, J.A. (1993) Clozapine-induced agranulocytosis. Incidence and risk factors in the United States. N. Engl. J. Med., 329, 162-167.

American Diabetes Association (2014) Diagnosis and classification of diabetes mellitus. Diabetes Care, 37 Suppl 1, S81-90.

Appiani, F., Carroll, B.T., Munoz, C. \& Trecco, J. (2011) Clozapine-induced weight loss? Ann. Clin. Psychiatry, 23, 225.

Asenjo Lobos, C., Komossa, K., Rummel-Kluge, C., Hunger, H., Schmid, F., Schwarz, S. \& Leucht, S. (2010) Clozapine versus other atypical antipsychotics for schizophrenia. Cochrane Database Syst. Rev., CD006633.

American Psychiatric Association (2013) Diagnostic and statistical manual of mental disorders $\left(D S M-5^{\circledR}\right)$, American Psychiatric Association Publishing, USA.

Atkin, K., Kendall, F., Gould, D., Freeman, H., Liberman, J. \& O'Sullivan, D. (1996) Neutropenia and agranulocytosis in patients receiving clozapine in the UK and Ireland. $\mathrm{Br} . \mathrm{J}$. Psychiatry, 169, 483-488.

Balda, M.V., Garay, O.U., Papale, R.M., Bignone, I., Bologna, V.G., Brandolini, A., Prokopez, C.R., Balasini, J.I., Baldessarini, R.J. \& Daray, F.M. (2015) Clozapine-associated neutropenia and agranulocytosis in Argentina (2007-2012). Int. Clin. Psychopharmacol., 30, 109-114.

Casey, D.E. (2004) Dyslipidemia and atypical antipsychotic drugs. J. Clin. Psychiatry, 65 Suppl 18, 27-35.

Chakos, M., Lieberman, J., Hoffman, E., Bradford, D. \& Sheitman, B. (2001) Effectiveness of second-generation antipsychotics in patients with treatment-resistant schizophrenia: a review and meta-analysis of randomized trials. Am. J. Psychiatry, 158, 518-526.

Cohen, D. \& Correll, C.U. (2009) Second-generation antipsychotic-associated diabetes mellitus and diabetic ketoacidosis: mechanisms, predictors, and screening need. J. Clin. Psychiatry, 70, 765-766.

Copolov, D.L., Bell, W.R., Benson, W.J., Keks, N.A., Strazzeri, D.C. \& Johnson, G.F. (1998) Clozapine treatment in Australia: a review of haematological monitoring. Med. J. Aust., 168, 495-497.

Correll, C.U., Brevig, T. \& Brain, C. (2019) Patient characteristics, burden and pharmacotherapy of treatment-resistant schizophrenia: results from a survey of 204 US psychiatrists. BMC Psychiatry, 19, 362.
Diabetes Prevention Program Research Group (2015) HbAlc as a predictor of diabetes and as an outcome in the diabetes prevention program: a randomized clinical trial. Diabetes Care, $\mathbf{3 8 ,}$ 51-58.

Enomoto, T., Ito, T., Sekine, K., Yasui, R., Ashizawa, Y., Uju, Y., Hayakawa, T. \& Tsukada, K. (2013) Clinical experience with clozapine in 55 cases of treatment-resistant schizophrenia. Seishin Shinkeigaku Zasshi, 115, 953-966.

Galletly, C.A., Clark, C.R., McFarlane, A.C. \& Weber, D.L. (1997) Relationships between changes in symptom ratings, neurophysiological test performance and quality of life in schizophrenic patients treated with clozapine. Psychiatry Res., 72, 161-166.

Grace, J., Bellus, S.B., Raulin, M.L., Herz, M.I., Priest, B.L., Brenner, V., Donnelly, K., Smith, P. \& Gunn, S. (1996) Longterm impact of clozapine and psychosocial treatment on psychiatric symptoms and cognitive functioning. Psychiatr. Serv., 47, 41-45.

Hanwella, R., de Silva, V., Wijeratne, C., Ketharanathan, T. \& de Silva, J. (2010) Clozapine-associated weight loss. J. Psychopharmacol., 24, 1127-1129.

Hayes, R.D., Downs, J., Chang, C.K., Jackson, R.G., Shetty, H., Broadbent, M., Hotopf, M. \& Stewart, R. (2015) The effect of clozapine on premature mortality: an assessment of clinical monitoring and other potential confounders. Schizophr. Bull., 41, 644-655.

Henderson, D.C., Cagliero, E., Gray, C., Nasrallah, R.A., Hayden, D.L., Schoenfeld, D.A. \& Goff, D.C. (2000) Clozapine, diabetes mellitus, weight gain, and lipid abnormalities: a fiveyear naturalistic study. Am. J. Psychiatry, 157, 975-981.

Henderson, D.C., Daley, T.B., Kunkel, L., Rodrigues-Scott, M., Koul, P. \& Hayden, D. (2004) Clozapine and hypertension: a chart review of 82 patients. J. Clin. Psychiatry, 65, 686-689.

Henderson, D.C., Nguyen, D.D., Copeland, P.M., Hayden, D.L., Borba, C.P., Louie, P.M., Freudenreich, O., Evins, A.E., Cather, C. \& Goff, D.C. (2005) Clozapine, diabetes mellitus, hyperlipidemia, and cardiovascular risks and mortality: results of a 10-year naturalistic study. J. Clin. Psychiatry, 66, 11161121.

Inada, K., Oshibuchi, H., Ishigooka, J. \& Nishimura, K. (2018) Analysis of clozapine use and safety by using comprehensive national data from the Japanese clozapine patient monitoring service. J. Clin. Psychopharmacol., 38, 302-306.

Kang, B.J., Cho, M.J., Oh, J.T., Lee, Y., Chae, B.J. \& Ko, J. (2006) Long-term patient monitoring for clozapine-induced agranulocytosis and neutropenia in Korea: when is it safe to discontinue CPMS? Hum. Psychopharmacol., 21, 387-391.

Kodama, K., Tojjar, D., Yamada, S., Toda, K., Patel, C.J. \& Butte, A.J. (2013) Ethnic differences in the relationship between insulin sensitivity and insulin response: a systematic review and meta-analysis. Diabetes Care, 36, 1789-1796.

Koller, E., Schneider, B., Bennett, K. \& Dubitsky, G. (2001) Clozapine-associated diabetes. Am. J. Med., 111, 716-723.

Lally, J. \& McDonald, C. (2011) Dramatic weight loss associated with commencing clozapine. BMJ Case Rep., 2011, bcr0920114790.

Lambertenghi Deliliers, G. (2000) Blood dyscrasias in clozapinetreated patients in Italy. Haematologica, 85, 233-237.

Lehman, A.F., Lieberman, J.A., Dixon, L.B., McGlashan, T.H., Miller, A.L., Perkins, D.O. \& Kreyenbuhl, J.; American Psychiatric Association and Steering Committee on Practice Guidelines (2004) Practice guideline for the treatment of patients with schizophrenia, second edition. Am. J. Psychiatry, 161, 1-56.

Leucht, S., Corves, C., Arbter, D., Engel, R.R., Li, C. \& Davis, J.M. (2009) Second-generation versus first-generation antipsychotic drugs for schizophrenia: a meta-analysis. Lancet, 373, 31-41.

Lewis, S.W., Barnes, T.R., Davies, L., Murray, R.M., Dunn, G., 
Hayhurst, K.P., Markwick, A., Lloyd, H. \& Jones, P.B. (2006) Randomized controlled trial of effect of prescription of clozapine versus other second-generation antipsychotic drugs in resistant schizophrenia. Schizophr. Bull., 32, 715-723.

Lieberman, J.A. \& Safferman, A.Z. (1992) Clinical profile of clozapine: adverse reactions and agranulocytosis. Psychiatr. Q., 63, 51-70.

McEvoy, J.P., Lieberman, J.A., Stroup, T.S., Davis, S.M., Meltzer, H.Y., Rosenheck, R.A., Swartz, M.S., Perkins, D.O., Keefe, R.S., Davis, C.E., Severe, J. \& Hsiao, J.K.; CATIE Investigators (2006) Effectiveness of clozapine versus olanzapine, quetiapine, and risperidone in patients with chronic schizophrenia who did not respond to prior atypical antipsychotic treatment. Am. J. Psychiatry, 163, 600-610.

Meltzer, H.Y. (1994) An overview of the mechanism of action of clozapine. J. Clin. Psychiatry, 55 Suppl B, 47-52.

Meltzer, H.Y. (1997) Treatment-resistant schizophrenia: the role of clozapine. Curr. Med. Res. Opin., 14, 1-20.

Meltzer, H.Y., Alphs, L., Green, A.I., Altamura, A.C., Anand, R., Bertoldi, A., Bourgeois, M., Chouinard, G., Islam, M.Z., Kane, J., Krishnan, R., Lindenmayer, J.P. \& Potkin, S.; International Suicide Prevention Trial Study Group (2003) Clozapine treatment for suicidality in schizophrenia: International Suicide Prevention Trial (InterSePT). Arch. Gen. Psychiatry, 60, 82-91.

Meltzer, H.Y., Burnett, S., Bastani, B. \& Ramirez, L.F. (1990) Effects of six months of clozapine treatment on the quality of life of chronic schizophrenic patients. Hosp. Community Psychiatry, 41, 892-897.

Meyer, J.M. \& Koro, C.E. (2004) The effects of antipsychotic therapy on serum lipids: a comprehensive review. Schizophr. Res., 70, 1-17.

Nielsen, J., Skadhede, S. \& Correll, C.U. (2010) Antipsychotics associated with the development of type 2 diabetes in antipsychotic-naive schizophrenia patients. Neuropsychopharmacology, 35, 1997-2004.

Nucifora, F.C. Jr., Mihaljevic, M., Lee, B.J. \& Sawa, A. (2017) Clozapine as a model for antipsychotic development. Neurotherapeutics, 14, 750-761.

Rummel-Kluge, C., Komossa, K., Schwarz, S., Hunger, H., Schmid, F., Lobos, C.A., Kissling, W., Davis, J.M. \& Leucht, S. (2010) Head-to-head comparisons of metabolic side effects of second generation antipsychotics in the treatment of schizo- phrenia: a systematic review and meta-analysis. Schizophr. Res., 123, 225-233.

Saha, S., Chant, D., Welham, J. \& McGrath, J. (2005) A systematic review of the prevalence of schizophrenia. PLoS Med., 2, e141.

Sernyak, M.J., Gulanski, B., Leslie, D.L. \& Rosenheck, R. (2003) Undiagnosed hyperglycemia in clozapine-treated patients with schizophrenia. J. Clin. Psychiatry, 64, 605-608.

Solanki, R.K., Singh, P. \& Munshi, D. (2009) Current perspectives in the treatment of resistant schizophrenia. Indian J. Psychiatry, 51, 254-260.

Suzuki, Y., Mikami, T., Tajiri, M., Kunizuka, T., Abe, H. \& Someya, T. (2013) Effects of hospitalization in a psychiatric ward on the body weight of Japanese patients with schizophrenia. Int. J. Psychiatry Med., 45, 261-268.

Taipale, H., Mehtala, J., Tanskanen, A. \& Tiihonen, J. (2018) Comparative effectiveness of antipsychotic drugs for rehospitalization in schizophrenia: a nationwide study with 20 -year follow-up. Schizophr. Bull., 44, 1381-1387.

Taylor, D.M. \& McAskill, R. (2000) Atypical antipsychotics and weight gain: a systematic review. Acta Psychiatr. Scand., 101, 416-432.

Thomas, N., Ravan, J.R., Jebaraj, P. \& Braganza, D. (2009) Clozapine producing weight loss: a case series with possible clinical implications: a hypothesis. J. Postgrad. Med., 55, 317.

Tiihonen, J., Lönnqvist, J., Wahlbeck, K., Klaukka, T., Niskanen, L., Tanskanen, A. \& Haukka, J. (2009) 11-year follow-up of mortality in patients with schizophrenia: a population-based cohort study (FIN11 study). Lancet, 374, 620-627.

Tiihonen, J., Mittendorfer-Rutz, E., Majak, M., Mehtälä, J., Hoti, F., Jedenius, E., Enkusson, D., Leval, A., Sermon, J., Tanskanen, A. \& Taipale, H. (2017) Real-world effectiveness of antipsychotic treatments in a nationwide cohort of 29823 patients with schizophrenia. JAMA Psychiatry, 74, 686-693.

Tungaraza, T.E. (2016) Significant weight loss following clozapine use, how is it possible? A case report and review of published cases and literature relevant to the subject. Ther. Adv. Psychopharmacol., 6, 335-342.

Webster, A. \& Ingram, L. (2013) A weight off the mind: clozapine and profound weight loss. Aust. NZ J. Psychiatry, 47, 12121213. 